\title{
Supercharging of Diesel Engine with Compressed Air: Experimental Investigation on Greenhouse Gases and Performance for a Hybrid Wind-Diesel System
}

\author{
Hussein Ibrahim ${ }^{1}$, Mohamad Issa ${ }^{2}$, Richard Lepage ${ }^{3}$, Adrian Ilinca², Jean Perron ${ }^{3}$ \\ ${ }^{1}$ Institut Technologique de Maintenance Industrielle, Sept-Îles, Canada \\ ${ }^{2}$ Department of Engineering, Université du Québec à Rimouski, Rimouski, Canada \\ ${ }^{3}$ Department of Engineering, Université du Québec à Chicoutimi, Chicoutimi, Canada \\ Email: ^Hussein.Ibrahim@itmi.ca, Mohamad_Issa@uqar.ca
}

How to cite this paper: Ibrahim, H., Issa, M., Lepage, R., Ilinca, A. and Perron, J. (2019) Supercharging of Diesel Engine with Compressed Air: Experimental Investigation on Greenhouse Gases and Performance for a Hybrid Wind-Diesel System. Smart Grid and Renewable Energy, 10, 213-236.

https://doi.org/10.4236/sgre.2019.109014

Received: September 2, 2019

Accepted: September 27, 2019

Published: September 30, 2019

Copyright $\odot 2019$ by author(s) and Scientific Research Publishing Inc. This work is licensed under the Creative Commons Attribution International License (CC BY 4.0).

http://creativecommons.org/licenses/by/4.0/

\begin{abstract}
Supercharging is the process of supplying air for combustion at a pressure greater than that achieved by natural or atmospheric induction, as applied to internal combustion engines. As a consequence of demonstrated technological, economical and energetic advantages in multiple literature evaluations concerning the large scale wind-compressed air hybrid storage system with gas turbines, the utilization of a hybrid wind-diesel system with compressed air storage (HWDCAS) has been frequently explored. These will mainly have average or small scale application such as the powering of isolated sites. It has been proven in numerous studies that the HWDCAS combined with an additional supercharging of the diesel engines will contribute to the increase of the power and efficiency of the diesel engine, the reduction of both fuel consumption and the emission of greenhouse gases (GHG). This article presents the obtained results from experimental validation of the selected design with an aim to valorize this innovative solution and become trustworthy.
\end{abstract}

\section{Keywords}

Wind Energy, Diesel Generator, Compressed Air Energy Storage, Supercharging, Hybrid Systems, Optimization

\section{Introduction}

Wind Energy has the largest growth rate among all renewable energies that contribute to electricity generation (more than $30 \%$ annually for the last five years 
[1]). This is due to a competitive production cost (compared to other traditional sources), for the reduction of GHG emission, the positive impact on employment, the technological development and the creation of wealth. In Quebec, in parallel to an effervescence of wind energy mostly as large wind farms connected to the national grid, the distribution of electricity to isolates sites is still a major technological and financial challenge. Apart from isolated locations, there are countless technical, tourist, agricultural, fish farming and military facilities that are not connected to the provincial or national energy grid. Moreover, power transmission is very difficult due to prohibitive costs of electricity lines. In these remote areas, diesels are used to generate electricity. This electricity production is relatively inefficient, disadvantageous and responsible for the emission of large amounts of GHG. With the growth of fossil fuels and the high cost of transportation, the financial losses are enormous. For example, Hydro-Quebec estimates its losses related to the subsidies responsible for delivering electricity to 14,000 clients scattered in forty communities that are not connected to the main electric grid to be in the order of 133 million Canadian dollars annually [2]. These deficits reflect the gap between the high cost of local electricity production and the consistent price of electrical energy.

Furthermore, it is estimated that 140,000 tons of GHG emissions (Gases that trap heat in the atmosphere such as carbon dioxide, methane and water vapour are called greenhouse gases) result from the use of diesel generators by subscribers of the autonomous grid of Quebec. This is equivalent to the GHG emissions from 35,000 vehicles that run $15,000 \mathrm{~km}$ annually [2]. In contrast, most of these communities are situated in regions with high wind energy potential. Wind diesel high-penetration systems (WDS) without storage are those where the production of wind power exceeds the charge for long periods. This enables the diesel engines to stop completely during those periods, leading to a substantial decrease in fuel consumption. The use of wind-diesel hybridization (WDH) at these autonomous grids could consequently, reduce the exploitation deficits by encouraging the use of the wind resource as a local, free "fuel", instead of diesel, which is an imported fuel [3] [4] [5]. In addition, studies have been conducted to analyze the different constraints related to the introduction of wind power in these isolated zones and consequently propose a technological solution, which, on one side, will adapt to the technical and financial challenges, and on the other side, adopted by the major stakeholders-the utilities, the government and the local population. These studies have confirmed the profitability of the WDH will be achieved if the penetration of wind energy is high enough. This can only be achieved if a storage system is implemented [6]. On the other hand, the utilities and the government, concerned about the security of power distribution to isolated sites, consider the WDH as a young and moderately reliable, whereas manufacturers, developers and researches regard it as a mature technology [7]. Hence, we have proposed a solution which replies to these technological and financial requirements while ensuring the reliability of the electricity distribution to these isolate sites-the use of the hybrid wind-diesel with compressed air 
energy storage system (HWDCAS) [8]. Before Pneumatic-Diesel hybridization with compressed air storage is commonly exploited, we highlight the different storage techniques exploited in the last decade and the effect of diesel engine boosting.

\subsection{Thermal Storage}

Thermal storage is used to generate electricity, even when the sun doesn't shine. Solar plants can concentrate heat from the sun and store energy in water, molten salts, or other fluids. Subsequently, this stored energy is used to produce electricity, allowing even after sunset to use solar energy. Plants such as these are presently working or being suggested in California, Arizona and Nevada [9]. For instance, the suggested Rice Solar Energy Project in Blythe, California will use a molten salt storage system with a concentrated solar tower to supply energy to roughly 68,000 households annually [10].

\subsection{Hydrogen Storage}

Hydrogen can be used for generation as a zero-carbon fuel. Excess electricity can be used to produce hydrogen that can later be stored and used in fuel cells, motors or gas turbines to produce electricity without damaging emissions [9]. The National Renewable Energy Laboratory has researched the ability to create wind hydrogen and store it for electricity generation in the wind turbine towers when the wind does not blow [11].

\subsection{Pumped Hydraulic Storage}

Pumped hydroelectric storage, by storing surplus electricity for subsequent use, provides a way to store energy at the transmission point of the grid. There are two reservoirs at distinct altitudes in many hydroelectric power plants. These crops store energy when supply exceeds demand by pumping water into the upper reservoir. When demand exceeds supply, by running downhill through turbines to produce electricity, the water is released into the reduced reservoir.

\subsection{Fly-Wheels}

By storing electricity in the form of a spinning mass, flywheels can provide the grid with a multitude of advantages at either the transmission or distribution stage. The unit is shaped like a cylinder and has inside a vacuum a big rotor. The rotor accelerates to very elevated speeds when the flywheel draws power from the grid, storing the electricity as rotational energy. The rotor switches to generation mode to discharge the stored energy, slows down and operates on inertial energy, bringing electricity back to the grid [12].

\subsection{Batteries}

Batteries can also be used to store energy on a big scale, such as those in a flashlight or cell phone. Like flywheels, batteries can be situated anywhere so that 
they are often seen as distribution storage when a battery plant is situated close customers to provide energy stability; or end-use, like electric vehicle batteries. There are many distinct kinds of batteries that have the ability to store large amounts of energy, including sodium sulfur, metal air, lithium ion, and lead acid batteries. In wind farms, there are several battery facilities; including the Notrees Wind Storage Demonstration Project in Texas, which utilizes a 36 MW battery plant to make the power supply stable even when the wind is not blowing [13] [14].

\subsection{Compressed Air}

The use of compressed air as a power storage agent is well implemented to both wind and diesel generation. In fact, the compressed air stored in reservoirs during periods of excess production of wind energy (strong winds) is injected in the diesel generators during periods of low wind energy production (light or no wind regimes), the outcome will be energy increase or consumption decrease for the same load [15]. Hence, this hybrid system will react in real time to assure, in an optimized manner, the balance between the generated and consumed power [16] as it is the case for gas turbines which will be discussed in the following paragraph.

\subsection{Effects of Diesel Engine Boosting}

To achieve a high energy output, the boosting systems are used to raise the intake pressure from these motors. The goal is to improve the volumetric efficiency of an engine by increasing the intake gas density (usually air). The compressor of the turbocharger brings in ambient air and compresses it at enhanced pressure before it enters the intake manifold. This results in a higher mass of air on each intake stroke entering the cylinders. Without raising energy, a turbocharger can also be used to boost fuel efficiency [17]. This is accomplished by diverting fuel waste power from the process of combustion and feeding it back into the "warm" intake side of the turbo that spins the turbine. The cold intake turbine (the other side of the turbo) compresses new intake air and pushes it into the intake of the engine as the warm turbine side is powered by the exhaust energy. By using this otherwise wasted energy to boost air mass, it becomes simpler to guarantee that all fuel is burned before the exhaust phase begins to be vented. The greater pressure temperature provides a greater Carnot efficiency [18].

\section{Why to Choose Compressed Air as Energy Storage System for High Penetration in Wind-Diesel System?}

Among all the methods for storing intermittent renewable energy, such as pumped hydroelectric storage, batteries, flywheels and CAES (compressed air storage), the latter has an overwhelming benefit given its low price, low effect on the environment and high efficiency [19]. CAES is a technology that has already 
been used at large scale, in pilot projects in Germany and few states of USA such as Alabama, Ohio and in a planned project at Texas (3000 MW project) for hybrid wind-natural gas power plants in the order of hundreds to thousands MW (Figure 1). Combining a storage component with a high-penetration WDS makes it possible to store the frequently occurring and otherwise dissipated surplus wind energy and then use it later when necessary. Therefore, the demand for fuel energy is decreased. Figure 2 shows that fuel savings begin when wind speeds exceed $4 \mathrm{~m} / \mathrm{s}$. When wind speed reaches $9 \mathrm{~m} / \mathrm{s}$, wind power is sufficient to meet the requirement of customers without the contribution of a diesel engine. However, when a 30 percent margin is reached between consumer demand and accessible wind power, the diesel engine is stopped. Excess wind power is lost for wind speeds greater than $9 \mathrm{~m} / \mathrm{s}$. According to [15] [16] [19], the annual fuel consumption for a WDS with air storage is estimated at 50\% with a $38 \%$ decreases in the fluctuation of energy production.

This enables a significant increase in the penetration of wind energy, to about $90 \%$ [15]. The additional cost of the CAES, in the order of $0.01 \$ / \mathrm{KWh}$ is largely compensated by the reduction (around $80 \%$ ) of natural gas consumption, carbon credits and the credits related to wind energy production [15].

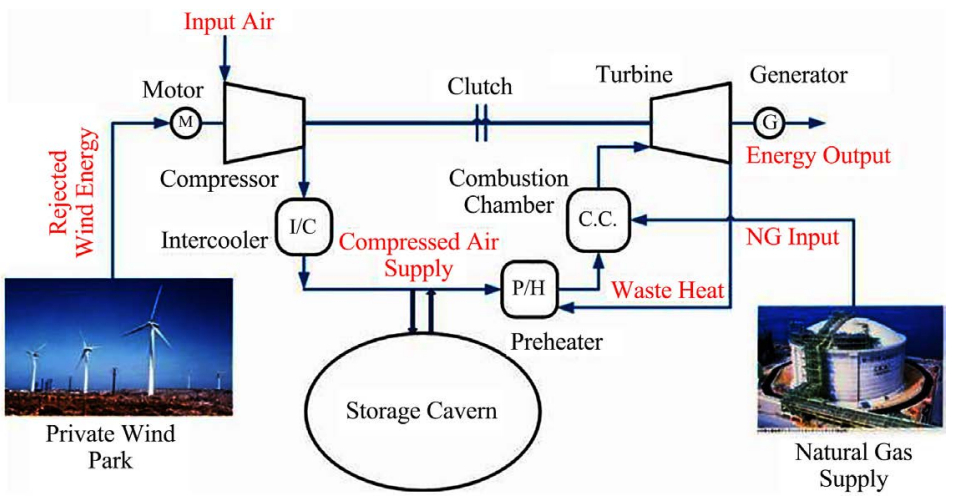

Figure 1. Illustration of the Wind-CAES hybrid system on a large scale.

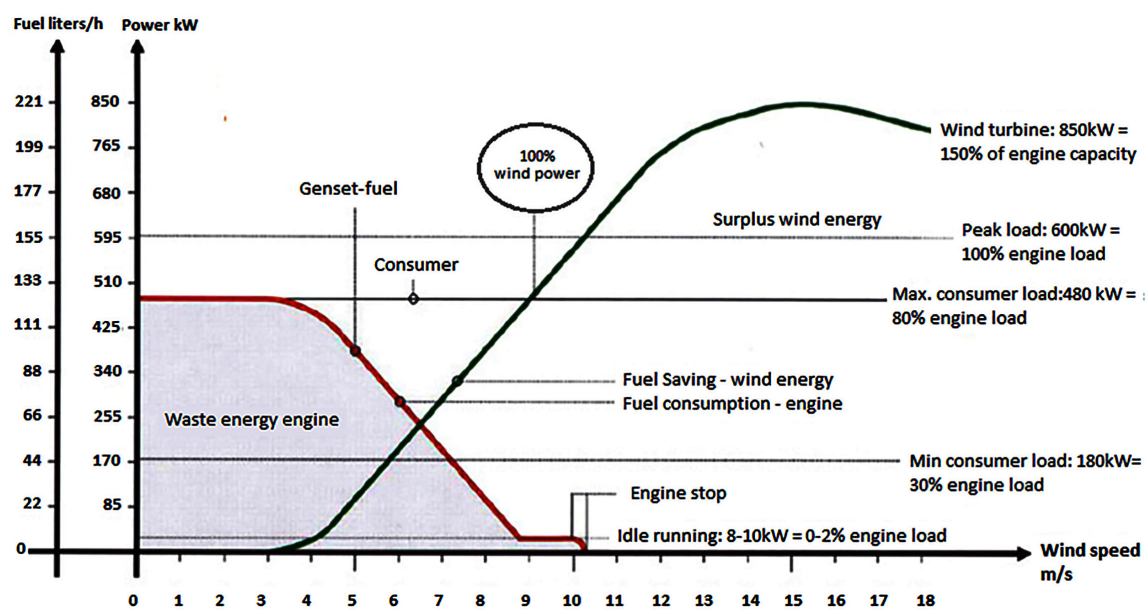

Figure 2. A high-penetration wind-diesel generator's power contribution and fuel consumption [19]. 
The compressed air storage energy-to-power ratio could be freely selected. The tank size, a standard industrial product, determines the energy content and the size of the engine/generator [15]. Compressed air is generally used to produce electricity by driving a compressed air motor or gas turbine [15]. In our project, we are exploring another option of using the already installed Diesel engine to exploit the stored compressed air. This method is called diesel engine pneumatic hybridization. CAES would make the diesel engine operate at some working points with less fuel consumption or even no fuel injection.

\section{Description of the Hybrid Wind-Diesel Compressed Air Energy Storage System (HWDCAS)}

The stored compressed air is used in the HWDCAS scheme to overload the diesel engines which consequently increases the wind energy penetration rate (WEPR). Supercharging is a method consisting of a preliminary compression with the aim of increasing motors' air intake density to boost their specific power (energy by swept volume) [15]. Thus, during periods of powerful wind, the wind power surplus (when the wind power penetration rate defined as the quotient between the wind power generated and the charge exceeds $1, \mathrm{WPPR}>1$ ) is used to compress and store the air via a compressor. The compressed air is then used to overload the diesel engine with a double benefit of enhancing its energy and reducing fuel consumption. The diesel generator operates during periods of low wind speed when there is insufficient wind power for the load [15] [16] [19]. Figure 3 illustrates the principle of such operation.

Pneumatic diesel engine hybridization involves using the stored compressed air to overload the diesel engine. This could be performed using multiple techniques to enhance diesel engine filling through the additional overload associated with the current turbo compressor. Seven systems have been explored among which, at least four demonstrate originality in the design of the diesel engines. These methods are: 1) the use of an air turbine in series with the axis of the turbo compressor (Figure 4); 2) the double stage turbocharging; 3) upstream admission in the compressor; 4) the hyperbar supercharging (Figure 5); 5) direct injection in the engine via the intake valve; 6) supercharging using the pressurized LENOIR cycle [20] and 7) supercharging with downsizing.

\section{Technical Benefits of Diesel Engine Pneumatic Hybridization}

Due to their efficiency, reliability, versatility and low price, diesel engines are merely the most economical solution in the range of energy requirements up to $300 \mathrm{MW}$ of the multiple ideas available for power supply in independent grids [15]. To provide a reaction to pollutants and laws on greenhouse emissions, much research is being performed globally to enhance the diesel engine's vigorous efficiency. Over the past decade, the efficiency of the direct injection diesel motor has risen significantly, primarily owing to turbo charging and reduction 
techniques [15]. A typical diesel engine's worldwide efficiency is actually around $40 \%[16]$.

On the other hand, the majority of diesel generators used in distant regions are already fitted with turbochargers. However, during low regime operation, this sort of scheme loses its benefits because its effectiveness is directly linked to the exhaust gas amount. To understand the advantage of an additional turbocharging of diesel engine and the operation limits of a turbocharger, we present in Figure 6 an example which compares a diesel engine in two functioning modes: atmospheric (without turbocharger) and turbocharged.

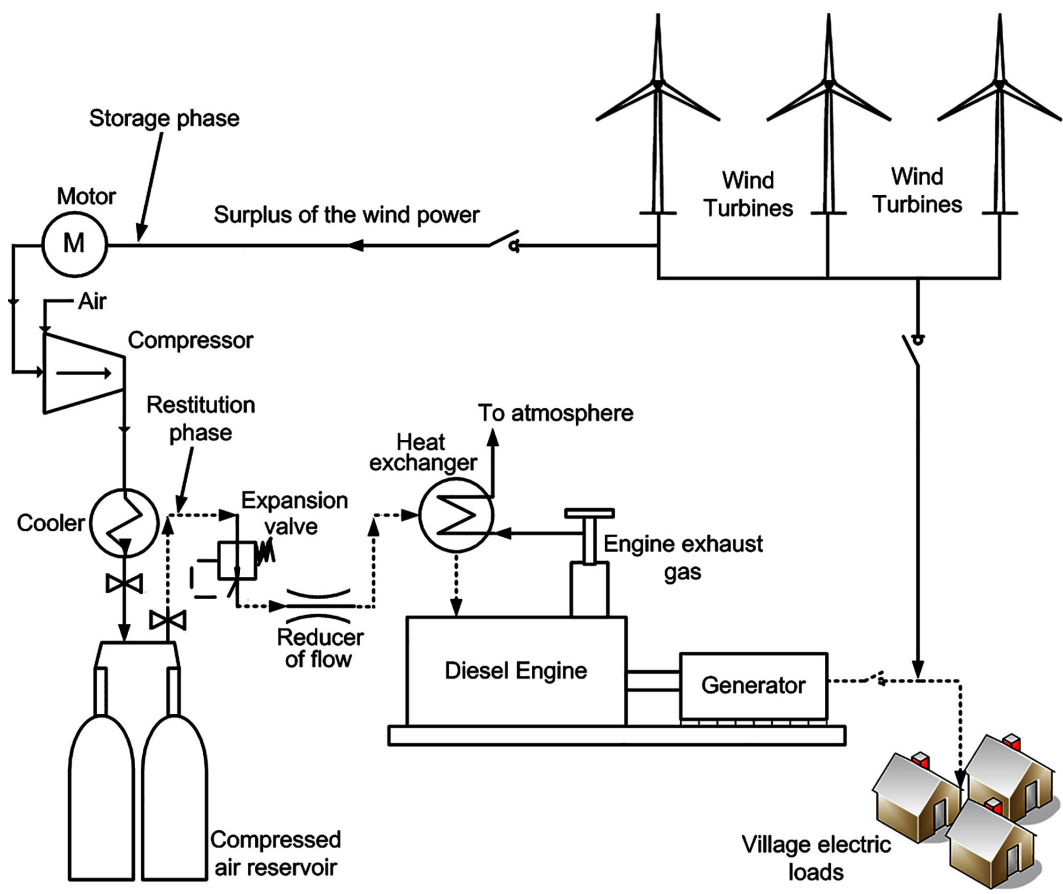

Figure 3. Illustration of the HWDCAS system.

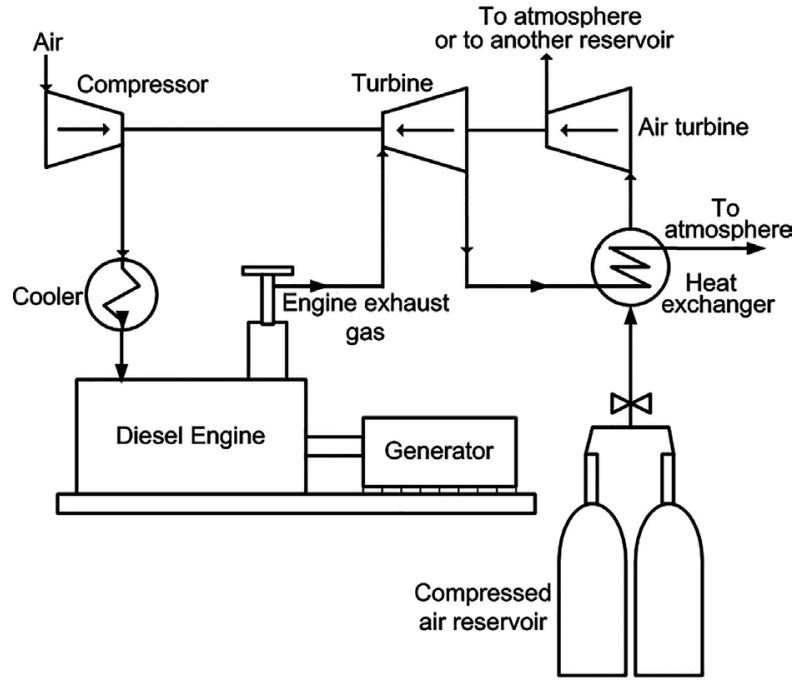

Figure 4. Illustration of the series use of an air turbine with a turbocharger [8]. 


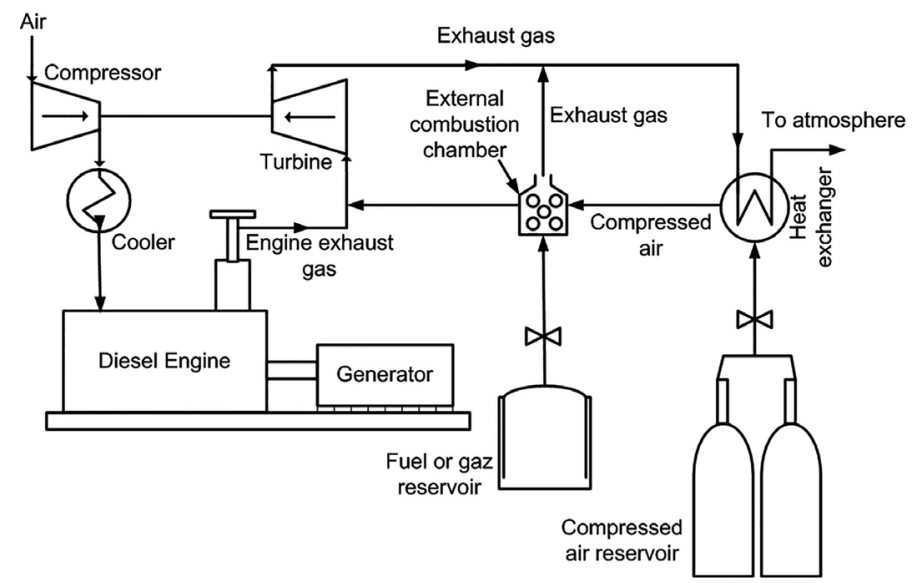

Figure 5. Illustration of the hyperbar supercharger [8].

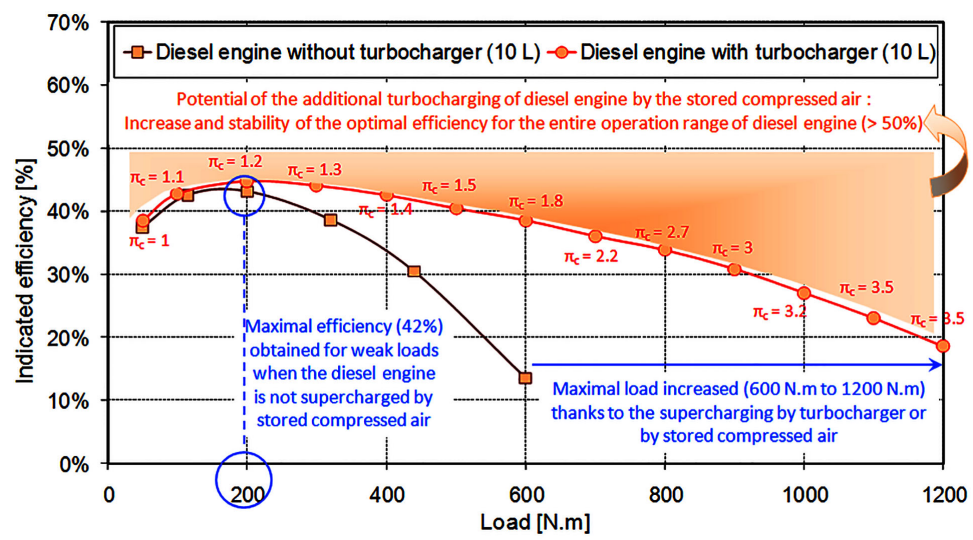

Figure 6. Possibility of extra $300 \mathrm{~kW}$ supercharging, $1500 \mathrm{rpm}$ diesel engine by compressed air stored.

Figure 6 shows that as compared to an atmospheric $300 \mathrm{~kW}, 1500 \mathrm{rpm}$ diesel engine, with a compression ratio of 16.3:1 and capacity of $10 \mathrm{~L}$, supercharging can improve the specified engine efficiency values (maximum efficiency $=45$ percent) and extend the high efficiency working variety thanks to the big permissible amount of air in the motor. The supercharged engine's effectiveness is about 38 percent for a load of 600 N.m compared to the atmospheric engine's effectiveness (14 percent), i.e. an increase of about 170 percent. Increasing the load applied to the engine, on the other side, causes a degradation of the diesel efficiency owing to the turbocharger's operating boundaries and increased heat loss through the cylinder walls. However, this does not exclude the fact that the effectiveness of elevated loads is greater than the effectiveness achieved with the atmospheric engine by supercharging (a rise of about 64 percent for a load of 1200 N.m).

Figure 6 also shows that the compression ratio reaches its maximal value only for the highest loads (this corresponds to high flow and pressure of exhaust gas). This delay in achieving the maximum compressed air pressure at engine intake will delay the accomplishment of the turbocharged engine's maximum energy. 
The objective of the additional supercharging via the stored compressed air is, then, to maximize the overall efficiency of the diesel engine (Figure 6), by Improving meaning, Reducing-meaning and Incrasing-meaning:

- Improving the effectiveness of combustion by always running the motor with an optimum air/fuel ratio that does not enable the turbocharger to function alone.

- Reducing pumping losses for the low-pressure loop of the diesel engine thermodynamic cycle to increase the work supplied for the same burned fuel quantity.

- Increasing the specific power (power per swept volume unit) of the diesel engine and its performance.

- Increase the intake pressure at the point allowing a reduction in the injected fuel amount while keeping the same maximum pressure in the motor cylinder. This enables mechanical and thermal limitations to be reduced owing to the overload.

\section{Experimental Validation}

Numerical modeling and simulations demonstrated the possibility of fuel economy by $30 \%-50 \%$ as a function of the wind potential, size of the engine and the used forced induction system [8] [15] [20] [21]. In order to valorize the design and make it more convincing and enable validation with obtained theoretical results, an experimental validation was necessary. For this reason, a test bench has been set up at the Université du Québec à Chicoutimi (UQAC). This bench includes a prototype of an atmospheric diesel engine (non-forced induced) with a $5 \mathrm{~kW}$ rating. This engine has been modified: a turbo compressor, as well as a forced induction system directly connected to the collector of the engine admission (using the compressed air circuit of UQAC), was installed. Several tests have been performed for different loads. The obtained results have proven the energetic, economic and ecologic potential of the new design. The new supercharging system has enabled the engine to operate with an efficiency of around $56 \%$ with the least possible fossil fuel so as to save around $35 \%$ of consumed fuel while perfectly ensuring the electrical demand without disturbing the quality of the electrical current (constant frequency and voltage). The losses are $9 \%$ under low load and $17 \%$ under a high load.

\subsection{Global Description of the Test Bench}

Recommendations from preliminary studies lead to the acquisition of a generator driven by an atmospheric non-forced induced diesel engine. This has enabled us to use a number of resistive loads connected to the generator as an applied load on the diesel engine and avoid the application of an external mechanical load (such as hydraulic brakes) on the shaft of the engine. The chosen diesel generator, a KCG-5000DES model from King Canada that has a power rating of $5.0 \mathrm{~kW}$ and a $7.35 \mathrm{~kW}$ thermal rating with an electrical starting system with a no load speed of $3600 \mathrm{rpm}$. 
Initially, the engine is not equipped with a turbo compressor. For this, a test bench has been set up to tolerate the conditions of the anticipated experience protocol while determining the size and type of the turbocharger which could be adapted for the admission and exhaust of the engine. An advantage of this option is its possibility to perform different trials: operate the engine as 1) an atmospheric engine; 2) a turbocharged engine via a turbo compressor; 3 ) or as a forced supercharged engine with pre-stored compressed air (supplementary supercharging). This test bench (Figure 7) includes an engine connected to a generator, a turbo compressor installed on the engine, engine monitoring sensors and a rapid data acquisition system. For logistics and financial reasons, the test bench did not include sensors to monitor pollutants. The installation is equipped with instrumentation ensuring: the secured operation of a test bench, the measurements in stationary and transitory regimes.

The engine is experimented in a cell which ensures the following functions: exhaust, cooling, fuel alimentation to the engine in fuel and security of the bench. The engine is completely instrumented and the entire signals are recorded on a calculator by the means of an acquisition card. The details of the sensors and measurements are presented later.

The used sensors, as well as the measured parameters are represented in the synoptic illustration of the test bench in Figure 8, while Figure 9 embodies the test bench (sensors, regulator, compressed air circuits, etc.).

On the other hand, we used an industrial combustion analyzer (Testo 350 with $\pm 5 \%$ of accuracy) in order to analyze the Nitrogen Oxide (NOx), Sulfur dioxide $\left(\mathrm{SO}_{2}\right)$ and Carbon dioxide $\left(\mathrm{CO}_{2}\right)$ effect of supercharging. Figure 10 shows the combustion analyzer connected to the exhaust engine.

\subsection{Classification of Tests}

The performance trials are grouped into three categories:

1) Diesel engine without turbocharger with no additional supercharging (atmospheric mode), where fuel injection is automatically controlled by the engine.

2) Turbocharged engine with automatic control of the fuel injection.

3) Supercharged diesel engine only with the compressed air network of UQAC, where the amount of injected fuel in the combustion chamber is controlled by a manual system. The compressed air is injected straight into the intake manifold and transferred through the poppet valve (Figure 4) into the cylinder.

In each category, several tests have been performed by varying the applied load on the generator. It is important to mention that the regime of the turbocharger, the torque of the engine and the temperature of the cylinder have not been installed due to logistical, technical and budgetary constraints. However, the ambient temperature has been measured with the help of a numerical thermometer (the frequency of air temperature variation is not significant in a small time period). The atmospheric pressure is assumed constant and equal to 1 bar. 


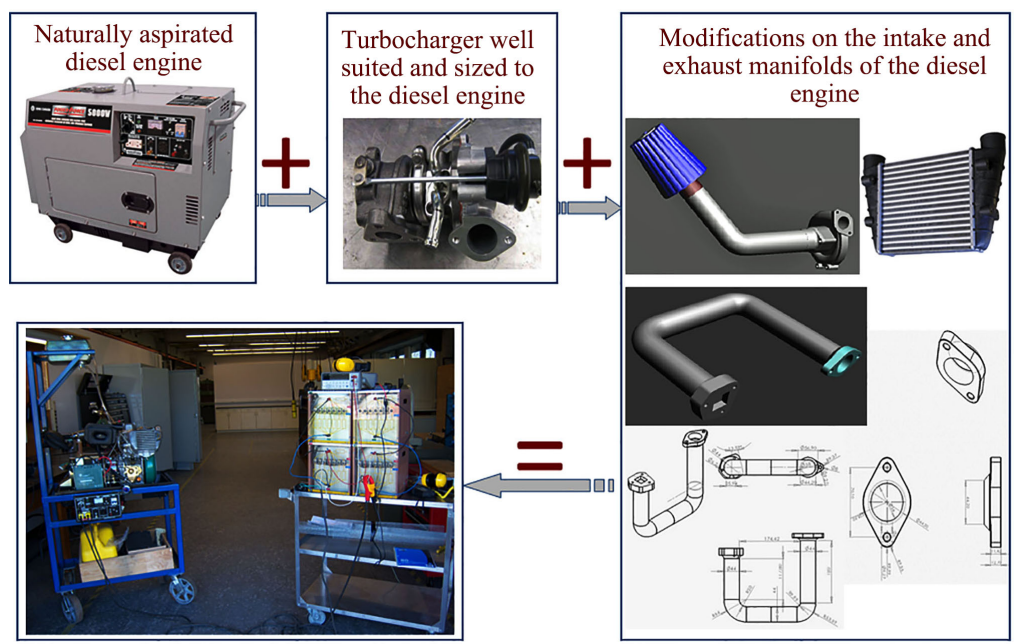

Figure 7. Different components of the test bench.

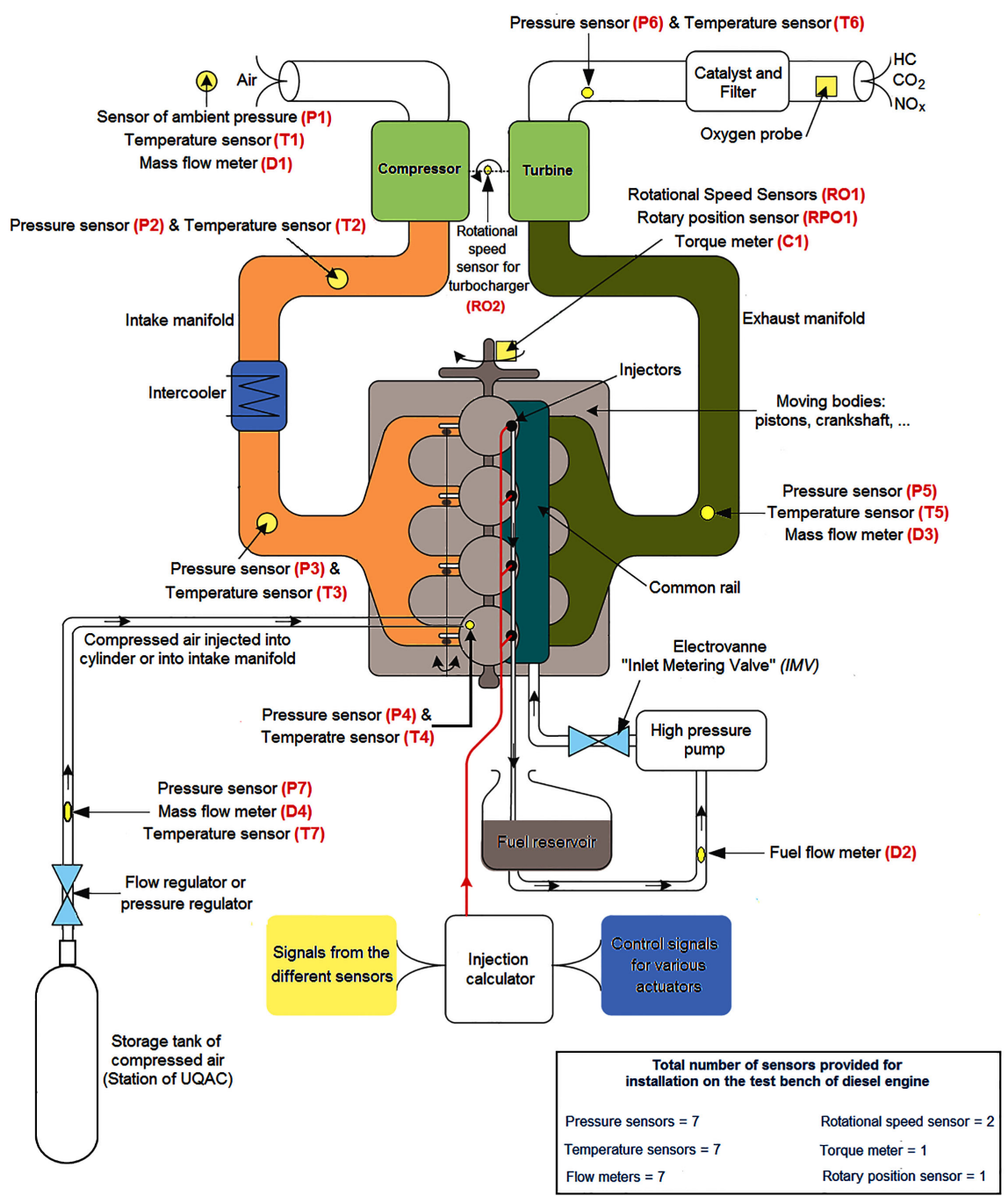

Figure 8. Synoptic illustration of the test bench. Pressure sensor accuracy: $\pm 2 \%$; Temperature sensor accuracy: $\pm 1 \%$; Flow meter accuracy: $\pm 1 \%$; Rotational speed sensor accuracy: $\pm 1 \%$; Torque meter accuracy: $\pm 0.5 \%$. 


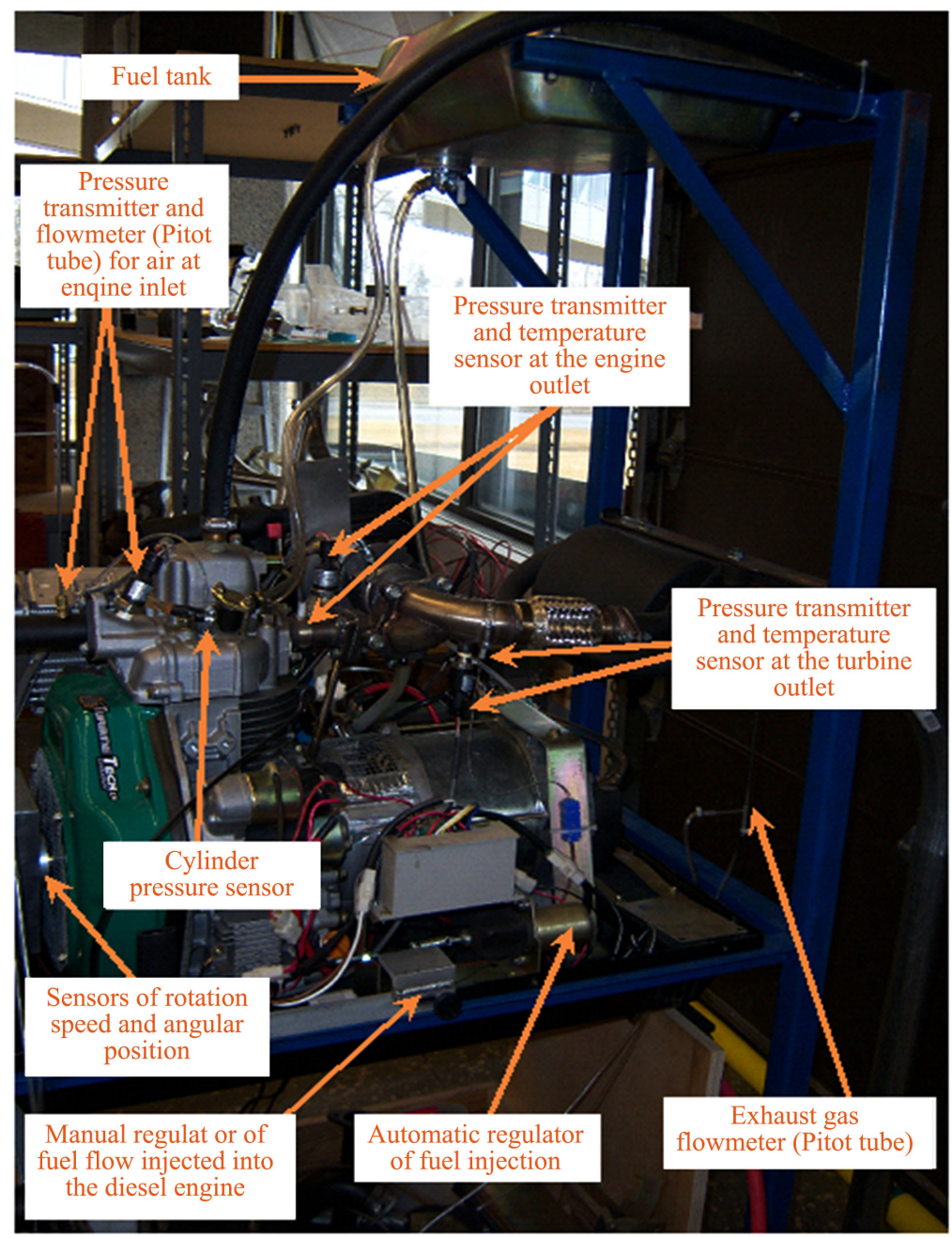

Figure 9. Different sensors and manual injection regulators installed on the engine.

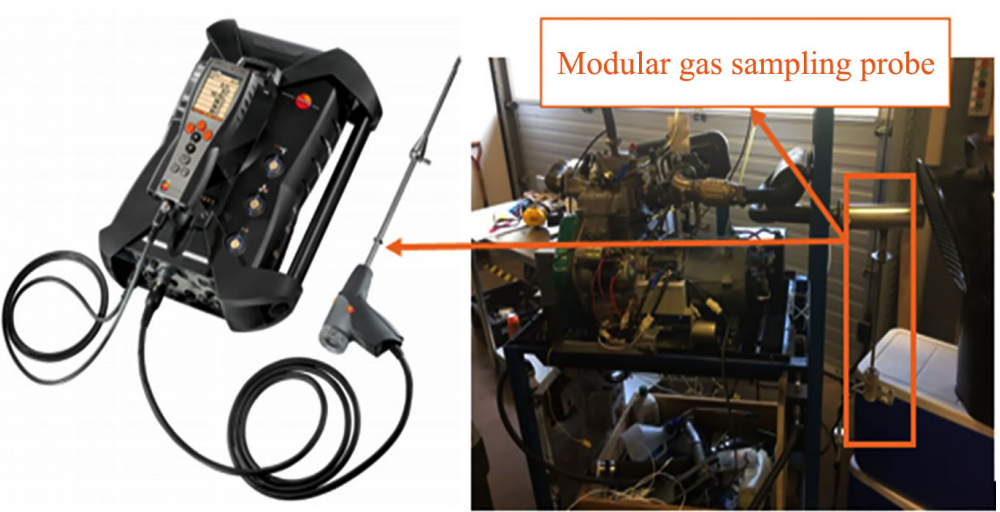

Figure 10. Illustration of the Testo 350 with the probe connected to the exhasut DE.

\section{Results and Discussions}

The results obtained from the tests performed on the diesel engine in atmospheric mode, with turbocharging and with additional supercharging are represented in Figures 11-19. 


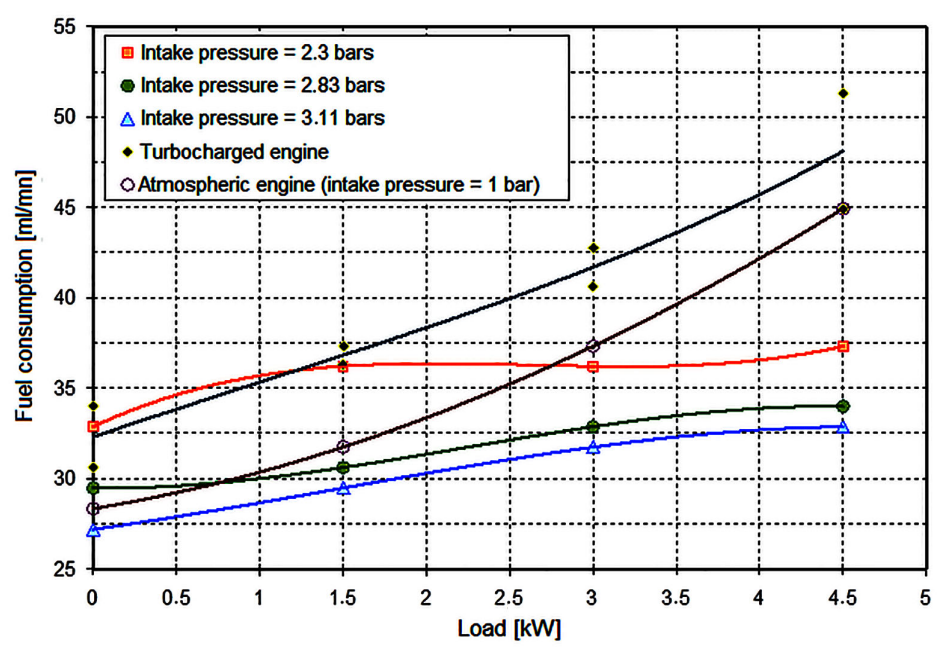

Figure 11. Consumption variation of diesel engine.

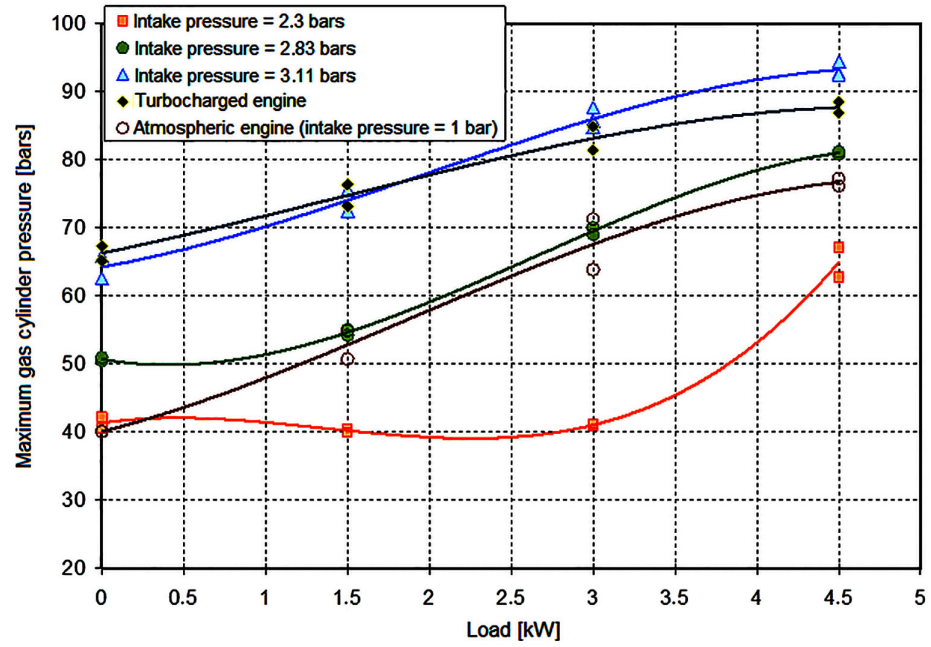

Figure 12. Maximum pressure variation in the cylinder.

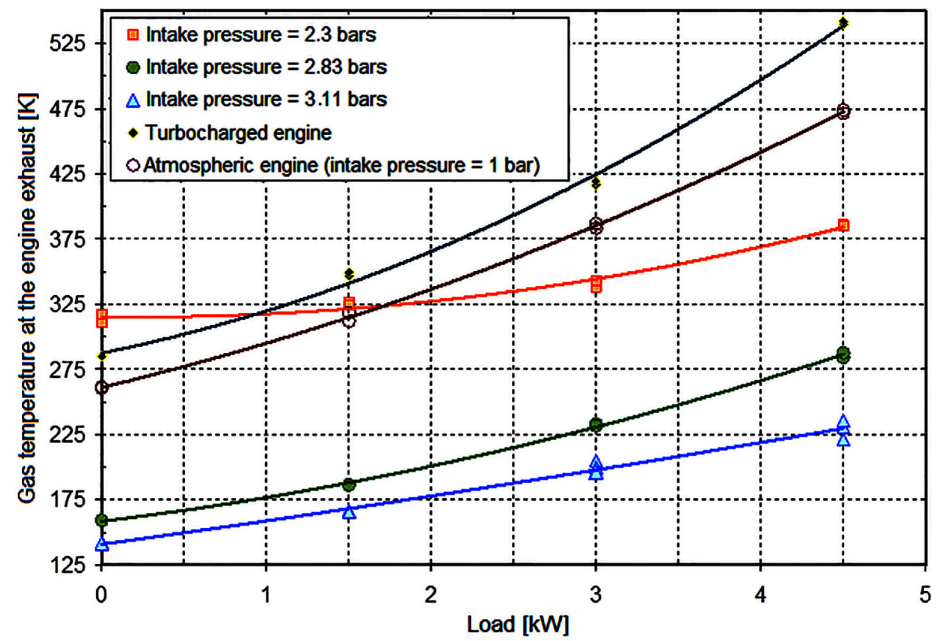

Figure 13. Variation of the exhaust gases. 


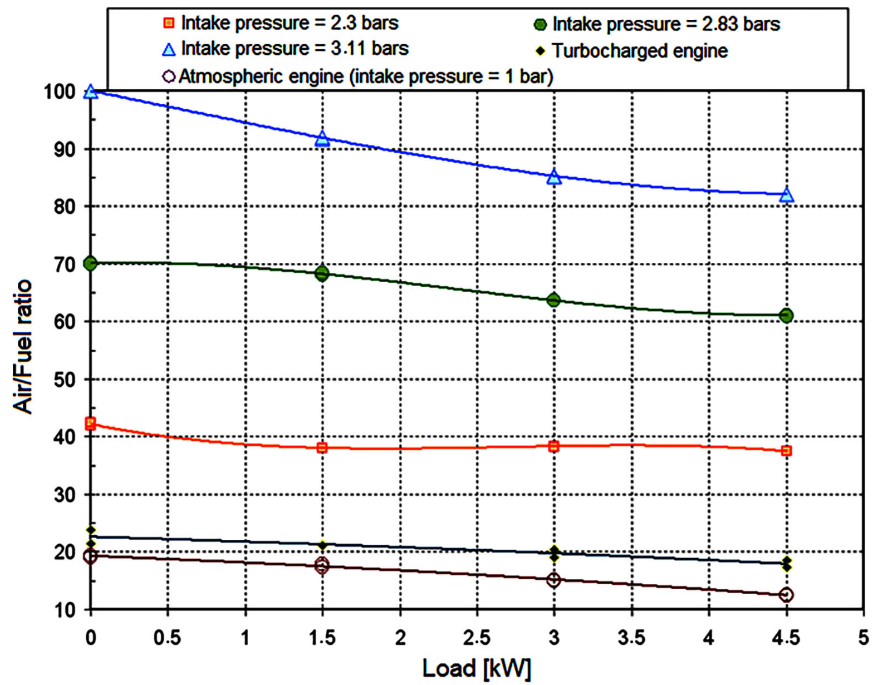

Figure 14. Air/Fuel ratio variation.

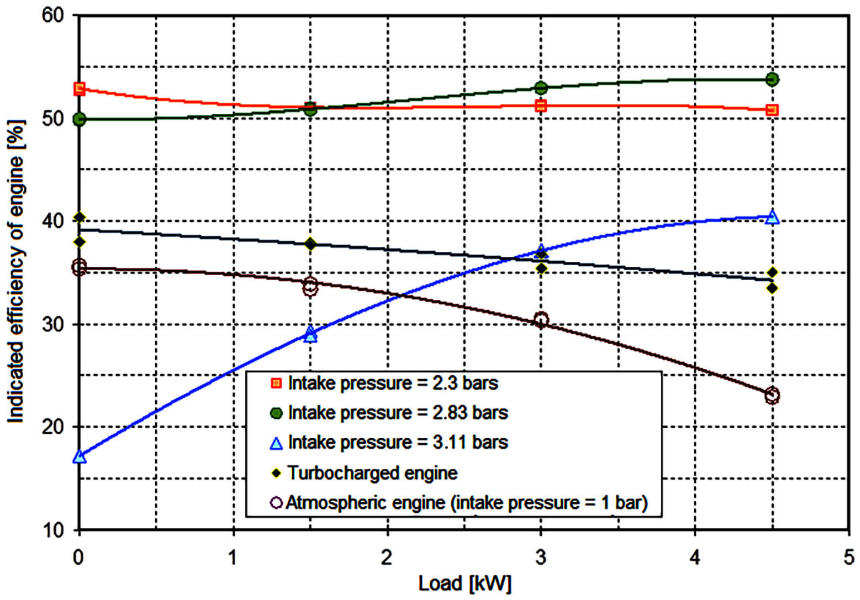

Figure 15. Variation of the indicated effciency function of load.

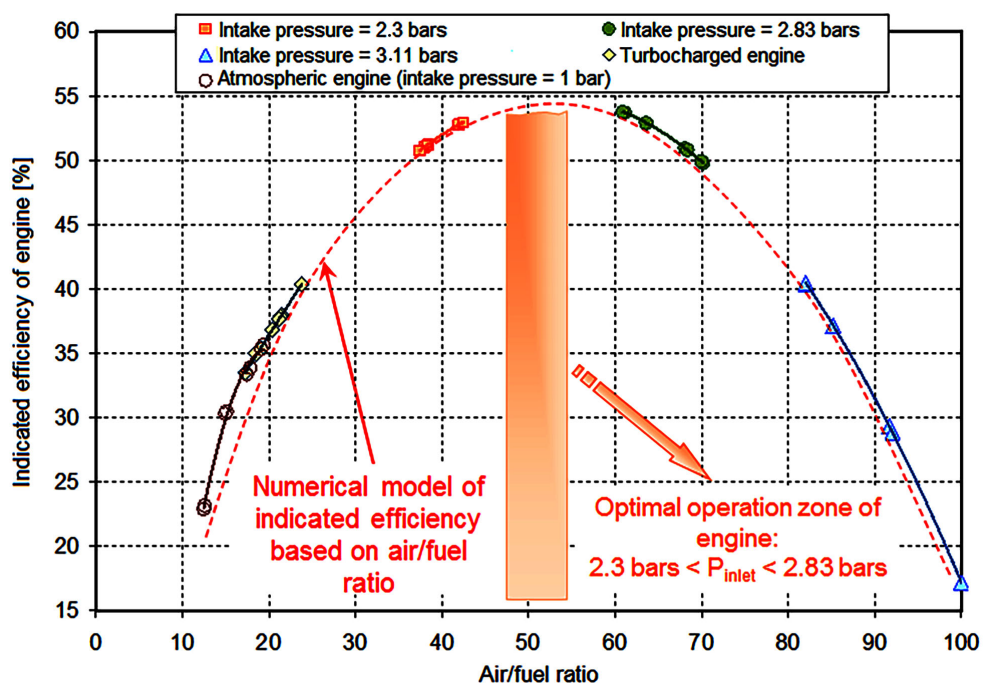

Figure 16. Variation of the effciency in function of air/fuel ratio. 


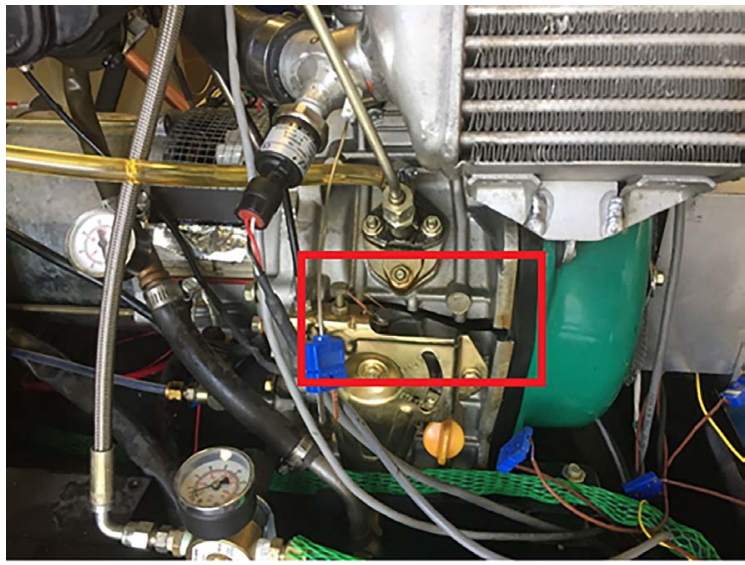

Figure 17. Illustration of the damage (engine is melted) due to the high pressure ( 3.11 bars $>2.83$ bars) applied in supercharging.

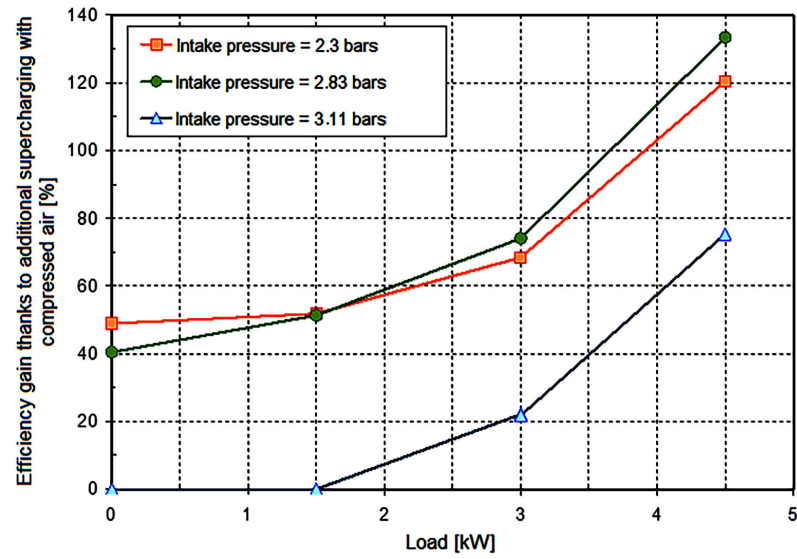

Figure 18. Efficiency gain due to hybrid forced induction in comparison to atmospheric mode operation.

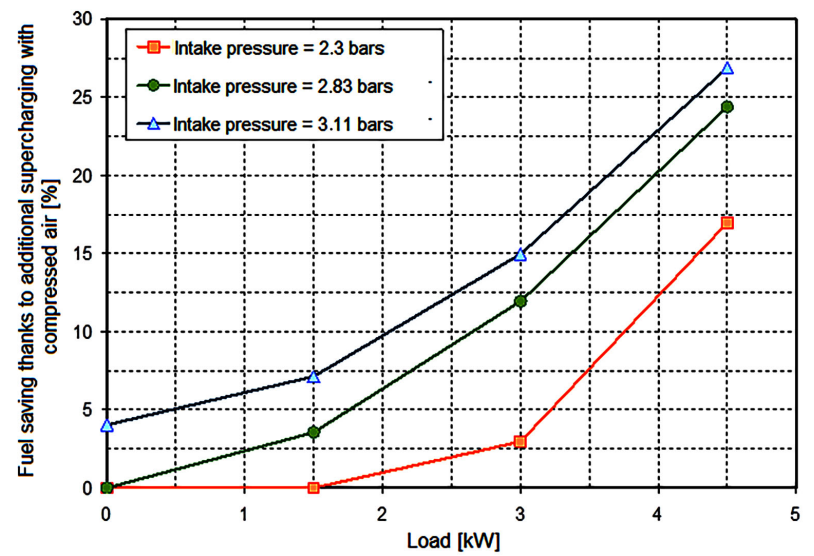

Figure 19. Fuel saving due to hybrid forced induction in comparison to atmospheric mode operation.

\subsection{Comparison According to Fuel Consumption}

Figure 11, which characterizes the fuel consumption, shows that regardless the 
operating mode of the engine (atmospheric, turbocharged by the turbo compressor alone or with the compressed air alone), the consumption of fuel increases with the increase of the load for the same pressure of admission in the engine. It is easy to see that for the whole operating range of the engine ( $0 \mathrm{~kW}$ to $4.5 \mathrm{~kW}$ ), the turbocharging of the engine by the turbo compressor triggers an increase of fuel consumption by about $11 \%$ compared to the quantity consumed by the engine in atmospheric mode. This is due to the fact that the turbo compressor increases the admitted air flow by the engine while forcing the latter to operate with a constant air/fuel ratio close to the stoichiometry.

Furthermore, the engine supercharged by compressed air from the network of UQAC consumes less fuel as the forced induced pressure increases. The rate of such decrease quenches with the growth of the admitted pressure as it is limited by constraints linked to the stability and homogeneity of the combustion. Moreover, this rate is virtually fixed, between two pressure levels, on the whole, operation range of the engine. By supercharging the engine with compressed air at 2.83 bars as admission pressure instead of 2.3 bars, the engine consumes, on average, $10 \%$ less fuel. However, if the additional supercharging is done at 3.11 bars, the engine consumes only $3.7 \%$ less fuel than it would, had it been alimented at 2.83 bars pressure. In a conclusion, $12 \%$ saving on fuel is made by forced inducing the engine at 3.11 bars instead of 2.3 bars.

\subsection{Comparison According to the Pressure in the Cylinder}

The variation of the maximum gas pressure in the cylinder is represented in Figure 14. First of all, we can easily see that as the power demand to the engine increases, the pressure in the cylinder increases more for all modes of operation. As an effect of the increased fuel consumption in turbo mode, it is clear that the pressure at the end of the combustion during this operation mode will be superior to that obtained for the atmospheric mode. An average increase of $30 \%$ can be seen in Figure 12.

However, the maximum pressure in the cylinder remains nearly constant (41 bars on average) in the working range between $0 \mathrm{~kW}$ and $3 \mathrm{~kW}$ for an induced pressure of 2.3 bars. However, an approximate increase of around $58 \%$ occurs for the maximum pressure when the engine operates between $3 \mathrm{~kW}$ and $4.5 \mathrm{~kW}$. This can be explained due to the fuel combustion performance which was better under $60 \%$ of load ( $3 \mathrm{~kW})$, while under a weak load (30\%), the compressed air injected into the engine compensated for the lack of fuel (weak ratio A/F) allowing for a close pressure between low load and medium load. When the engine is supercharged with compressed air at 2.83 and 3.11 bars pressure, the curves show an increase with respect to the load. By varying the pressure of admitted air in the engine between 2.3 bars 2.83 bars and 3.11 bars, respectively, the average increase in the maximum pressure in the cylinder due to forced induction at 2.83 bars is around $22 \%$ as compared to 2.3 bars. The same percentage is obtained when the supercharging is done at 3.11 bars instead of 2.83 bars. 
It is easily noted, according to Figure 12, that even with a high forced induction at 3.11 bars, a pressure twice as that produced by the turbocharger, the maximum pressure in the cylinder always remains in the acceptable limits of the engine even in the critical zone of operation of the engine (important loads). However, by operating without any load, the maximum pressure in the cylinder due to a forced induction at 3.11 bars is the same as that obtained for a forced induction via the turbo compressor but always remains superior to that obtained with the atmospheric engine. This enables us to conclude that the mechanical and thermal constraints that could limit the operation of the engine or even damage it have no more importance due to the fact that the choice of the turbocharger has accounted for all the constraints and that the supplementary forced induction has not exceeded the operation limits of the engine with a turbocharger.

In fact, the maximum pressure obtained for high loads is around 90 bars for both cases whereas the temperature of the exhaust gases is very much lower when the engine is forced-induced at 3.11 bars $\left(225^{\circ} \mathrm{C}\right)$ instead of using a turbocharger $\left(550^{\circ} \mathrm{C}\right)$ (Figure 13$)$. The thermal and mechanical constraints can then be neglected given that the maximum pressure in the cylinder is still far from the limit of the acceptable value of the engine (120 bars).

\subsection{Comparison According to the Air-Fuel Ratio}

Figure 14 represents the variations of the air/fuel ratio for a diesel engine, operating at different modes with respect to the charge. This Figure illustrates that the air/fuel ratio decreases with an increase in the load. However, this decrease becomes more and more significant with a secondary forced induction via the compressed air from the network of UQAC but the ratio always remains superior to that obtained with an atmospheric engine or that of a forced induced by a turbo compressor irrespective of the applied load.

It is important to notice that by forced induction the engine at 2.3 bars pressure, the air/fuel ratio decreases from 42 to 41 in a range situated between 0 and $1.5 \mathrm{~kW}$ and stabilizes at 41 for the rest of the operating range (from 1.5 to 4.5 $\mathrm{kW}$ ) whereas, in the case where the forced induction is done at 2.83 bars, the air/fuel ratio remains nearly constant around 70 when the load varies between 0 and $1.5 \mathrm{~kW}$ and it diminishes afterwards to reach a value of 61 when the engine drives a $4.5 \mathrm{~kW}$ load, an average drop of $11 \%$. However, by adopting 3.11 bars as pressure at the engine admission, the air/fuel ratio is subjected to a continuous drop with respect to the load where it passes through a value of 100 when the engine operates without load and reaches 82 for maximum operating load, a drop of around $18 \%$.

\subsection{Comparison According to Indicated Efficiency}

Figure 15 and Figure 16 illustrate for different operating modes, the variations of the indicated efficiency of the diesel engine with respect to the applied charge 
and the air/fuel ratio respectively. It is interesting to note that the efficiency diminishes with an increase of the load when the engine operates in atmospheric or turbo mode. However, by supercharging the engine by compressed air from the network of UQAC, the indicated efficiency of the diesel increases with increasing load and is much better and more stable for lower pressures at admission but superior to those produced by the turbo compressor.

Figure 15 shows that by forced induction of the engine with compressed air at 2.3 bars of pressure, the obtained efficiency is around $50 \%$ but increases to $54 \%$ if the admission pressure becomes 2.83 bars for both cases and for the whole range of engine operation. However, if the admission pressure increases further to reach a 3.11 bars pressure level, the efficiency increases with the load but does not exceed $40 \%$. Moreover, at this pressure level, the efficiency is too low, around $17 \%$, and when the engine is in free operation the efficiency is $28 \%$ with a connected load of $1.5 \mathrm{~kW}$. This can be explained by the unstable combustion process in a cylinder given that a large mass of air is admitted (air/fuel ratio being around 80 to 100), which has as consequence the degradation of the combustion and engine efficiency.

To conclude, it can be noticed that, according to Figure 15 and Figure 16, despite the advantages related to efficiency obtained by forced induction at high pressures, this method can lead to a poor operating mode of the engine and in consequence a degradation of the indicated efficiency. For these reasons, this type of forced induction is limited by:

- A maximum pressure level at admission should not exceed 2.83 bars in the case of an engine using this test bench. If this condition is not respected, the engine becomes inefficient mostly for average and small loads and/or damaged. It should be noted here that the engine was damaged when a pressure of 3.11 bars was applied to $4.5 \mathrm{~kW}(90 \%)$ of the load after 5 minutes of testing. This happened because the pressure in the cylinder exceeds the recommended limit for which the cylinder is designed for. Figure 17 shows the damage to the diesel engine.

- An air/fuel ratio ranging from 50 to 60 . If this ratio is smaller than this interval, the engine approaches stoichiometric operation and its efficiency will not exceed $35 \%$. If the air/fuel ratio is greater than this range, the engine will then operate in the combustion instability zone with an efficiency which does not exceed $40 \%$ even at full load.

\subsection{Efficiency Gain}

Figure 18 illustrates the obtained gain in efficiency as a consequence of compressed air at high pressure admitted in the cylinder as compared to atmospheric mode operation.

It is easy to notice that the forced induction engine at a pressure varying between 2.3 and 2.93 bars offers greater efficiency improvement for the whole range of operation and mostly for significant loads, thus, confirming the numerical demonstration. In this pressure interval, the engine efficiency can increase 
by about $50 \%$ if it is in free run operation as compared to atmospheric operating mode. This gain becomes remarkable at full load where it reaches a $130 \%$ level. This level has never been achieved in the past. However, the forced induction at 3.11 bars pressure, brings no gain in efficiency when the engine works with small loads (0 to $1.5 \mathrm{~kW})$, whereas the gain for significant loads $(4.5 \mathrm{~kW})$ does not exceed the $78 \%$ as compared to an atmospheric engine.

\subsection{Fuel Saving}

The evolution of fuel saving due to hybrid forced induction as compared to an atmospheric mode operating engine is illustrates in Figure 19.

It is clear that as the load increases, the fuel economy becomes more significant. Similarly, as the admission pressure increases, fuel saving increases. For a load of $4.5 \mathrm{~kW}$ and a 2.3 bars admission pressure, the engine saves $17 \%$ of fuel, around $24 \%$ for a 2.83 bars admission pressure and $27 \%$ economy for a 3.11 bars admitted pressure.

Furthermore, it can be noticed that the fuel economy decreases as the admitted air pressure increases. This is explained by the fact that the engine will operate in a zone where the efficiency of the combustion process will undergo degradation, thereby, making fuel economy difficult due to the quality and homogeneity of the combustion. Figure 20 illustrates another point: during free running mode, only forced induction at 3.11 bars enables a fuel economy of around $4 \%$. Moreover, the economic advantage of a forced induced engine at 2.3 bars as compared to an atmospheric mode operating engine appears only for loads of $1.5 \mathrm{~kW}$ power rating and higher.

\section{Impact of the Supercharging on Greenhouse Gases}

Emissions from diesel generators (DGs) such as $\mathrm{PM}, \mathrm{CO}_{2}, \mathrm{NO}_{\mathrm{x}}, \mathrm{SO}_{2}$ and $\mathrm{CO}$ contribute to diver's cardiovascular and respiratory diseases and cancer, in addition to water and soil pollution, visibility reductions and global climates changes [5] [16] [17] [18] [19] [22] [23] [24] [25].

In this context, we have evaluated and compared the emission of exhaust gases emitted by the DG before and after the supercharging mode using number 2 diesel fuel type B-ULS with maximum fuel sulfur of $15 \mathrm{mg} / \mathrm{kg}$. An industrial gas combustion analyzer (Testo 350) is used to evaluate carbon dioxide $\left(\mathrm{CO}_{2}\right)$, nitrogen oxide $\left(\mathrm{NO}_{\mathrm{x}}\right)$, sulfur dioxide $\left(\mathrm{SO}_{2}\right)$ and carbon monoxide $(\mathrm{CO})$ levels. Figure 20 illustrates the carbon dioxide level, while Figures 21-23 illustrate the nitrogen oxide, sulfur dioxide and carbon monoxide levels.

According to Figure 20, it is clear to notice that the forced induction of compressed air at a 2.25 bars pressure offers the best reduction of carbon dioxide by an amount of $41 \%$ approximately and this for the different levels of applied loads. This can be explained by the homogeneous charge compression ignition and fuel saving due to the supercharging resulting in high peak pressure but relatively lower peak temperature at 2.25 bars. 


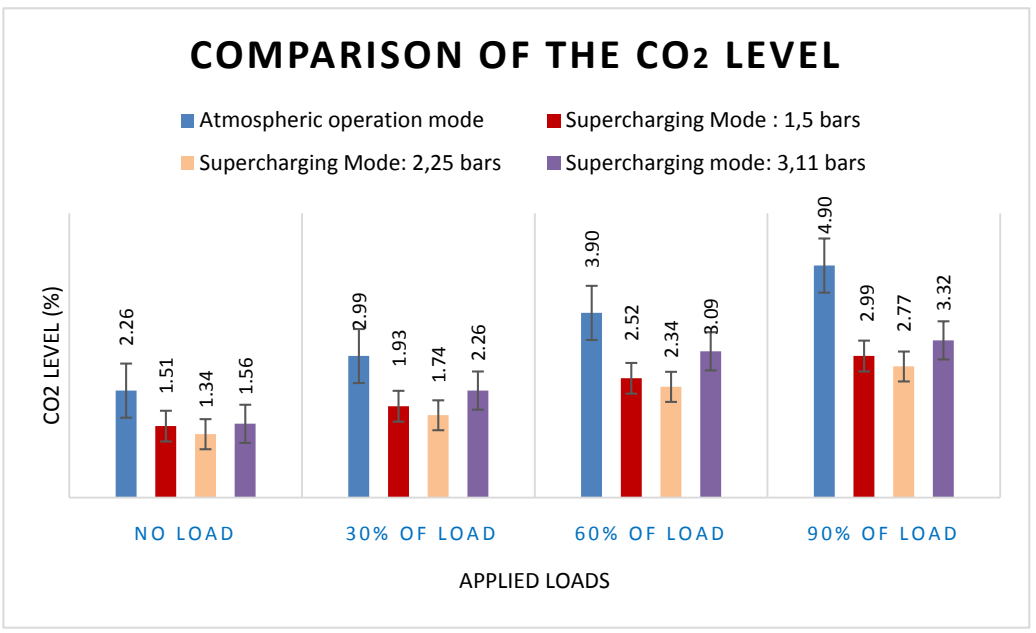

Figure 20. Carbon dioxide reduction due to hybrid forced induction in comparison to atmospheric mode operation.

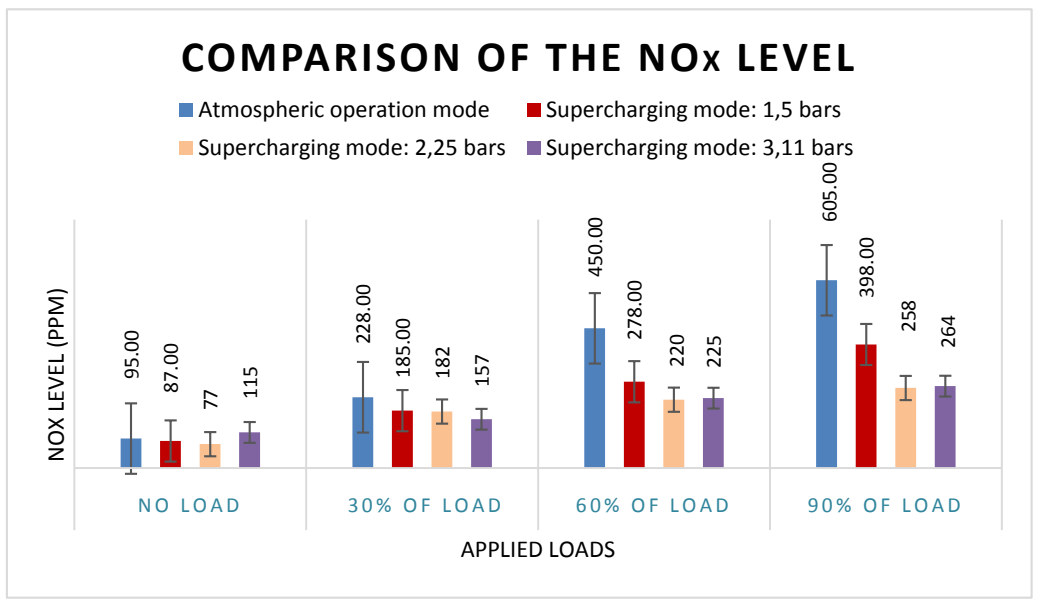

Figure 21. Nitrogen Oxyde reduction due to hybrid forced induction in comparison to atmospheric mode operation.

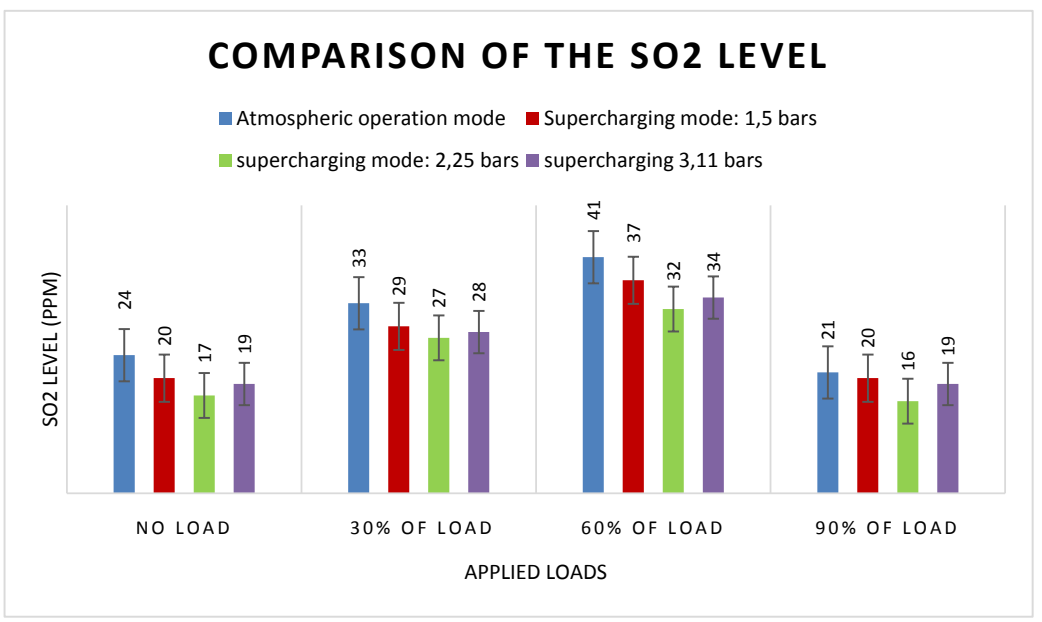

Figure 22. Illustration of the sulfur dioxide reduction due to hybrid forced induction in comparison to atmospheric mode operation. 


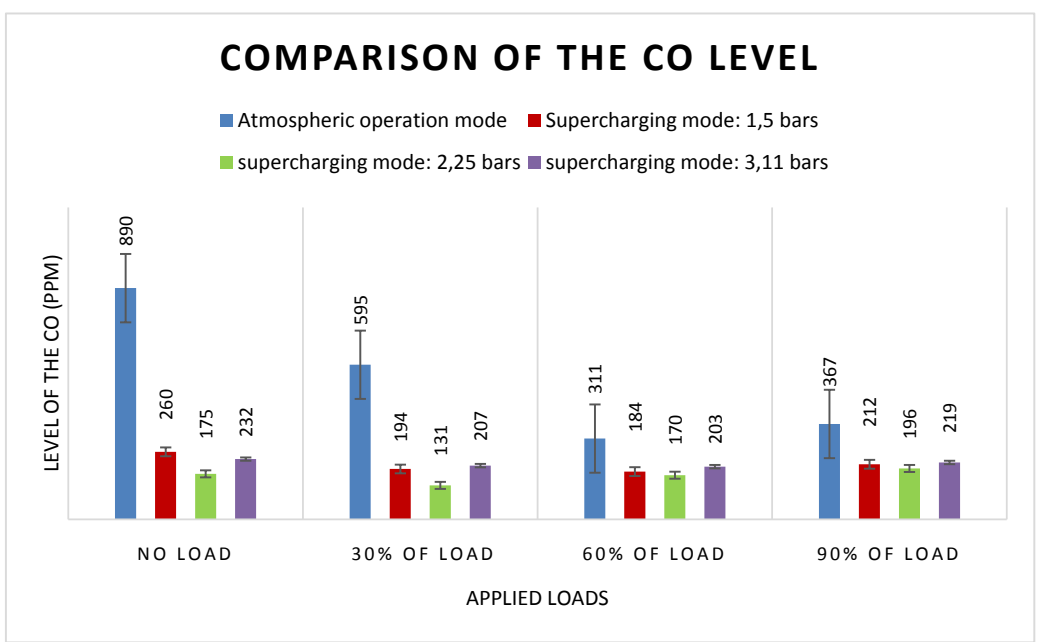

Figure 23. Illustration of the carbon monoxide reduction due to hybrid forced induction in comparison to atmospheric mode operation.

Figure 21 illustrates the evolution of the nitrogen oxide due to hybrid forced induction as compared to an atmospheric mode operating engine. It has been found that the NOx rate has decreased by an amount of $20 \%$ under low loads $(\leq 30 \%)$ and continue to drop further to reach $50 \%-55 \%$ approximately under $60 \%$ and $90 \%$ of applied loads due to the increase in combustion temperature associated with higher engine load. In addition, like carbon dioxide, the best NOx drop was observed at a 2.25 bars pressure and this for the different applied loads.

The characteristics of $\mathrm{SO}_{2}$ emission are shown in Figure 22. There is a decrease of sulfur dioxide emission on increase in the engine load. As shown in Figure 22, the $\mathrm{SO}_{2}$ decrease by $18 \%$ approximately under low loads $(\leq 30 \%)$ at 2.25 bars before to decrease further under medium (60\%) and high loads (90\%) by an amount of $22 \%-24 \%$. The higher combustion temperature at higher engine load combined with the reduction in fuel consumption due to the supercharging mode contributes the general decreasing trend. It can also be seen that the lowest recorded gas emission is below 2.3 bars due to the best ratio of Air/Fuel, efficiency of the system and combustion temperature. The increasing of the emission under high loads can be related to the efficiency of the system on the one hand, and to the quantity of fuel injected on the other hand.

It has been noted that losses increase as the load increases, while the efficiency diminishes with an increase of the load. Finally, Figure 23 shows the variation of carbon monoxide emission with engine load due to hybrid forced induction in comparison to atmospheric mode operation. It has been found that the $\mathrm{CO}$ emission during the atmospheric mode operation is highest at low loads $(\leq 30 \%)$ due to incomplete combustion of air-fuel mixture. On the other hand, supercharging with compressed air at 2.25 bars pressure reduces $\mathrm{CO}$ emissions by an amount of $45 \%$ under a medium and high load $(60 \%-90 \%)$ and up to $65 \%$ under low loads $(0 \%-30 \%)$. According to [20] and [21], it is possible that the 
excess oxygen contained in the fuel due to the supercharging enhances complete combustion in the cylinder and reduces further the $\mathrm{CO}$ emission.

\section{Conclusions}

The hybrid wind-diesel-compressed air system represents an innovative, ecological and very promising concept. The technical, economical and commercial potential of this system is very important for isolated regions in Quebec and elsewhere in the world as it is designed to eliminate most constraints that wind energy development encounters [7].

The test bench at UQAC has enabled us to experimentally validate the gain in power, efficiency, fuel economy and greenhouse gases emissions that a supplementary forced induction can offer to a $7.5 \mathrm{~kW}$ thermal power $/ 4.5 \mathrm{~kW}$ electrical power diesel engine. The obtained results have shown that in an interval between 2.25 and 2.83 bars, the efficiency of the engine can increase to approximately $50 \%$ if it is in free run mode as compared to an atmospheric engine. This gain becomes significant at full load where it reaches a 130\% level. Furthermore, application of supercharging of diesel engine with compressed air energy has shown a positive impact on GHGs reduction for $\mathrm{CO}_{2}, \mathrm{NO}_{\mathrm{x}}, \mathrm{SO}_{2}$, and $\mathrm{CO}$ by an average of $40 \%, 35 \%, 21 \%$ and $50 \%$ respectively. This has never been achieved before. In our future work, we will carry out extra tests by maintaining comparable lambda circumstances and further researching PM emissions.

\section{Conflicts of Interest}

The authors declare no conflicts of interest regarding the publication of this paper.

\section{References}

[1] World Wind Energy Association (2008) World Wind Energy Report 2008. http://educypedia.karadimov.info/library/worldwindenergyreport2008_s.pdf

[2] Gouvernement du Québec (2005) Énergie et Ressources naturelles Québec. https://mern.gouv.qc.ca/energie/energie-eolienne/

[3] Pinard, J.P. and Weis, T.M. (2003) Pre-Feasibility Analysis of Wind-Energy for Inuvialuit Region in the Northwest Territories. Aurora Research Institute, Report. https://nwtresearch.com/sites/default/files/inuvialuit-region-wind-energy-pre-feasi bility-study.pdf

[4] Issa, M., Ibrahim, H., Lepage, R. and Ilinca, A. (2019) A Review and Comparison on Recent Optimization Methodologies for Diesel Engines and Diesel Power Generators. Journal of Power and Energy Engineering, 7, 31-56. https://doi.org/10.4236/jpee.2019.76003

[5] Issa, M., Fiset, J., Ibrahim, H. and Ilinca, A. (2019) Eco-Friendly Selection of Diesel Generator Based on Genset-Synchro Technology for Off-Grid Remote Area Application in the North of Quebec. Energy and Power Engineering, 11, 232-247. https://doi.org/10.4236/epe.2019.115015

[6] Weis, T.M. and Ilinca, A. (2008) The Utility of Energy Storage to Improve the Economics of Wind-Diesel Power Plants in Canada. Renewable Energy, 33, 1544-1557. 
https://doi.org/10.1016/j.renene.2007.07.018

[7] Weis, T.M., Ilinca, A. and Pinard, J.P. (2008) Stakeholders' Perspectives on Barriers to Remote Wind-Diesel Power Plants in Canada. Energy Policy, 36, 1611-1621. https://doi.org/10.1016/j.enpol.2008.01.004

[8] Ibrahim, H., Ilinca, A., Younès, R., Perron, J. and Basbous, T. (2007) Study of a Hybrid Wind-Diesel System with Compressed Air Energy Storage. 2007 IEEE Canada Electrical Power Conference, Montreal, 25-26 October 2007, 320-325. https://doi.org/10.1109/EPC.2007.4520350

[9] Union of Concerned Scientists (2013) Ramping up Renewables: Energy You Can Count on.

https://www.ucsusa.org/resources/ramping-renewables

[10] Solar Reserve (2010) Rice. http://www.solarreserve.com/what-we-do/csp-projects/rice-army-airfield/

[11] Kottenstette, R., and Cottrell, J. (2003) Hydrogen Storage in Wind Turbine Towers. NREL/TP-500-34656. National Renewable Energy Laboratory, Golden, CO. http://www.nrel.gov/docs/fy03osti/34656.pdf

[12] Beacon Power (2013) Islands and Isolated Grids. http://www.beaconpower.com/

[13] Imre, G. (2013) Smoothing Renewable Wind Energy in Texas. Department of Energy. http://energy.gov/articles/smoothing-renewable-wind-energy-texas

[14] Electricity Storage Association (2013) Technologies of Energy Storage. http://www.electricitystorage.org/

[15] Ibrahim, H., Ilinca, A. and Perron, J. (2007) Comparison and Analysis of Different Energy Storage Techniques Based on Their Performance Index. 2007 IEEE Canada Electrical Power Conference, Montreal, 25-26 October 2007, 393-398. https://doi.org/10.1109/EPC.2007.4520364

[16] Ibrahim, H., Ilinca, A. and Perron, J. (2008) Energy Storage Systems-Characteristics and Comparisons. Renewable and Sustainable Energy Reviews, 12, 1221-1250. https://doi.org/10.1016/j.rser.2007.01.023

[17] HowStuffWorks (2000) What Is the Difference between a Turbocharger and a Supercharger on a Car's Engine?

[18] Feneley, A.J., Pesiridis, A. and Andwari, A.M. (2017) Variable Geometry Turbocharger Technologies for Exhaust Energy Recovery and Boosting-A Review. Renewable and Sustainable Energy Reviews, 71, 959-975.

https://doi.org/10.1016/j.rser.2016.12.125

[19] Basbous, T. (2013) Hybridation pneumatique d'un moteur diesel en vue de son utilisation dans un système hybride éolien-diesel avec stockage d'énergie sous forme d'air comprimé. Université du Québec à Chicoutimi, Québec. https://doi.org/10.1522/030565288

[20] Ibrahim, H., Younès, R., Ilinca, A., Dimitrova, M. and Perron, J. (2010) Study and Design of a Hybrid Wind-Diesel-Compressed Air Energy Storage System for Remote Areas. Applied Energy, 87, 1749-1762. https://doi.org/10.1016/j.apenergy.2009.10.017

[21] Ibrahim, H., Younès, R. and Ilinca, A. (2007) Optimal Conception of a Hybrid Generator of Electricity. CANCAM02007 ETS-39, Toronto, Canada, 358-359.

[22] Issa, M., Ibrahim, H., Ilinca, A. and Hayyani, M. (2019) A Review and Economic Analysis of Different Emission Reduction Techniques for Marine Diesel Engines. Open Journal of Marine Science, 9, 148-171. https://doi.org/10.4236/ojms.2019.93012 
[23] Issa, M., Ait-Yahia, K., Lepage, R., Ibrahim, H., Ilinca, A. and Ghandour, M. (2019) Integrated A Variable Frequency Drive for a Diesel-Generating Set Using the Genset-Synchro Concept. International Journal of Engineering Research \& Technology, 8, 232-239.

[24] Issa, M., Beaulac, P., Ibrahim, H. and Ilinca, A. (2019) Marinization of a Two-Stage Mixed Structured Packing Scrubber for Sox Abatement and $\mathrm{CO}_{2}$ Capture. International Journal of Advanced Research, 7, 73-82.

https://doi.org/10.21474/IJAR01/8793

[25] Mobarra, M., Fiset, J. and Ilinca, A. (2017) Modeling and Optimization of the Energy Production Based on Eo-Synchro. Power Engineer, 3, 3-9. 